\title{
BIBLIOGRAFIA
}

\section{Contribución a la Bibliografía de Juan Carlos Onetti}

La presente contribución a la bibliografía de Juan Carlos Onetti comprende dos partes. En la primera se recogen todas las obras de Onetti: cuentos, novelas y artículos periodísticos publicados con su nombre y con cinco seudónimos; se establece la cronología correcta de los cuentos y se incluyen varios cuentos desconocidos y nunca recogidos en libro hasta la fecha. En la segunda parte se reúne todo el material crítico conocido sobre la obra de Onetti.

Como siempre en la preparación de una bibliografía, varias personas han colaborado de una manera $\mathbf{u}$ otra, pero quisiera dejar constancia de mi agradecimiento a quienes más han contribuido a facilitar mi labor: al Dr. Enrico Cicogna, traductor de la obra de Onetti al italiano, por reseñas publicadas en Italia; a los críticos Jorge Ruffinelli y Rubén Cotelo, y a la Sra. Eloísa P. de Verani por hacerme llegar material crítico publicado en Montevideo; a la Srita. Nancy Devine y al personal de "Interlibrary Loans" de Mount Holyoke College por haber obtenido referencias bibliográficas no disponibles en dicha universidad. Y al "Faculty Grants Committee" de la misma institución por el apoyo económico con que secundaron mi tarea.

HUgo J. Verani

Mount Holyoke College 


\section{OBRAS DE ONETTI}

\section{Cuentos}

\section{Cronología}

1. "Avenida de Mayo-Diagonal-Avenida de Mayo", La Prensa (Buenos Aires), 1 enero 1933, sección octava, p. 4. Reproducido en Marcha (Montevideo), No. 519, 17 marzo 1950, p. 14. Primer premio del concurso de cuentos de La Prensa, compartido con otros nueve autores. [Nunca recogido en libro.]

2. "El obstáculo", La Nación (Buenos Aires), 6 octubre 1935, segunda sección, p. 3. [Nunca recogido en libro.]

3. "El posible Baldi", La Nación, 20 septiembre 1936, quinta sección, p. 2. [Nunca recogido en libro.]

4. "Convalescencia", Marcha, No. 34, 10 febrero 1940, sin numerar [tres páginas]. Primer premio del concurso de cuentos de Marcha, compartido con otros dos autores. Publicado con el seudónimo H. C. Ramos. [Nunca recogido en libro.]

5. "Un sueño realizado", La Nación, 6 julio 1941, $2^{\text {a }}$ sección, pp. 3 y 4. Reproducido en Marcha, No. 435, 2 julio 1948, pp. 14-15 y en el No. 436, 9 julio 1948, pp. 14-15.

6. "Mascarada", Apex (Montevideo), No. 2, febrero de 1943, pp. 4-7. Reproducido en La Nación, 4 abril 1943, 2a sección, p. 2. También en Marcba, No. 250, 15 septiembre 1944, pp. 14-15.

7. "La larga historia", Alfar (Montevideo), Año XXII, No. 84, 1944, sin numerar [seis páginas]. Reproducido en: A. Rama, ed., Montevideo en cuentos, Entrega No. III de Enciclopedia Uruguaya, Montevideo, Arca, 1968. Sobre este cuento elaborará Onetti su novela La cara de la desgracia de 1960.

8. "Bienvenido, Bob", La Nación, 12 noviembre 1944, 2a sección, pp. 2 y 4.

9. "Regreso al sur", La Nación, 28 abril 1946, 2" sección, p. 2. [Nunca recogido en libro.]

10. "Esbjerg, en la costa", La Nación, 17 noviembre 1946, 2a sección, p. 2.

11. "La casa en la arena", La Nación, 3 abril 1949, 2" sección, p. 4.

12. "El álbum", Sur, No. 219-20, enero-feb. 1953, pp. 66-79.

13. "Historia del Caballero de la Rosa y de la Virgen encinta que vino de Liliput", Entregas de la Licorne, No. 8, 1956, pp. 45-63. 
14. "El infierno tan temido", Ficción (Buenos Aires), No. 5, enerofebrero 1957, pp. 60-71.

15. "Jacob y el otro", en Ceremonia secreta y otros cuentos de América Latina, New York, Doubleday and Company, 1961, pp. 349-389. Mención en el concurso de Life en español.

16. "Justo el treintaiuno", Marcha, No. 1220, 28 agosto 1964, 2a sección, pp. 23-24.

17. "La novia robada", Papeles. Revista del Ateneo de Caracas, No. 6, 1968, pp. 7-23.

18. "Matías, el telegrafista", Marcha, No. 1560, 10 septiembre 1971, pp. 30-31. [Publicado antes, sin autorización del autor, en Macedonio (Buenos Aires), No. 8, 1970, pp. 37-52.]

\section{Novelas}

19. El pozo. Montevideo: Ediciones Signo, 1939, 99 p. $2^{\text {a }}$ ed., Montevideo: Editorial Arca, mayo de 1965. Seguido de: Angel Rama, "Origen de un novelista y de una generación literaria", pp. 57-110.

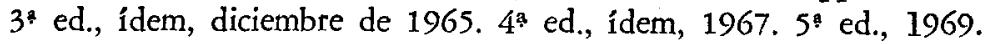
Otra edición; Cuaderno No. 48 de Enciclopedia Uruguaya, Montevideo: Arca, 1969.

20. Tierra de nadie. Buenos Aires: Losada, 1941, 253 p. [Dedicada a Julio E. Payró]. Segundo premio del concurso de novelas Ricardo Güiraldes. $2^{\mathrm{a}}$ ed., Montevideo: Ediciones de la Banda Oriental, 1965. 3: ed., idem, 1968. Otra edición; México: Universidad Veracruzana, 1967.

21. Para esta nocbe. Buenos Aires: Editorial Poseidón, 1943, 211 p. [Dedicada a Eduardo Mallea]. 2a ed., Montevideo: Arca, 1966. $3^{*}$ ed., idem, 1967, 4a ed., idem, 1971.

22. La vida breve. Buenos Aires: Sudamericana, 1950, 389 p. [Dedicada a Norah Lange y Oliverio Girondo]. $2^{\text {s }}$ ed., Buenos Aires: Sudamericana, 1968.

23. Los adioses. Buenos Aires: Sur, 1954, 88 p. [Dedicada a Idea Vilariño]. $2^{\mathrm{a}}$ ed., Montevideo: Arca, 1966, $3^{\mathrm{a}}$ ed., ídem, 1967, 4* ed., idem, 1970, seguido de Wolfgang Luchting, "El lector como protagonista de la novela", pp. 77-90.

24. Una tumba sin nombre. Montevideo: Ediciones Marcha, 1959, 82 p. [Dedicada a Litti]. 2" ed., Montevideo: Arca, 1967. [El título cambia: Para una tumba sin nombre]. $3^{\text {a }}$ ed., ídem., 1968. 
25. La cara de la desgracia. Montevideo: Editorial Alfa, 1960, 49 p. [Dedicada a Dorotea Muhr].

26. El astillero. Buenos Aires: Compañía Fabril Editora, 1961, 218 p. [Dedicada a Luis Batlle Berres]. 2" ed., Montevideo: Arca, 1967. Seleccionada en el concurso de novela de Fabril Editora. Otras ediciones; La Habana: Casa de las Américas, 1968. Prólogo de Mario Benedetti, pp. VII-X, y seguido de "J. C. Onetti y su época", pp. 231-245. Buenos Aires: Compañía Fabril Editora, 1969. Madrid: Salvat Editores con la colaboración de Alianza Editorial, 1970. Prólogo de José Donoso, pp. 11-15.

27. Tan triste como ella. Montevideo: Alfa, 1963, 92 p. [Dedicada a Martha Canfield]. Incluye La cara de la desgracia, pp. 45-92.

28. Juntacadáveres. Montevideo: Alfa, 1964, 275 p. [Dedicada a Susana Soca]. Finalista en el Premio Rómulo Gallegos. $2^{\mathrm{a}}$ ed., ídem, 1966. 3 ed., ídem, 1968. $4^{z}$ ed., ídem, 1970. Otra edición; Madrid: Publicaciones de la Revista de Occidente, 1969.

\section{Colecciones de Cuentos y Novelas}

29. Un sueño realizado y otros cuentos. Montevideo: Número, 1951, 66 p. Prólogo de Mario Benedetti, pp. 7-14. Recoge: 5, 8, 10 y 11.

30. El infierno tan temido. Cuentos. Montevideo: Ediciones Asir, 1962, 71 p. Recoge: 6, 12, 13, 14.

31. Jacob y el otro. Un sueño realizado y otros cuentos. Montevideo: Ediciones de la Banda Oriental, 1965, 93 p. Prólogo de Gabriel Saad, pp. 7-14. Recoge: 15 y 29. $2^{\text {? }}$ ed., 1971.

32. Tres novelas. Montevideo: Alfa, 1967, 132 p. Recoge: 15 y 27.

33. Cuentos completos. Buenos Aires: Centro Editor de América Latina, 1967, 224 p. No recoge: 1, 2, 3, 4, 7 y 9.

34. La novia robada y otros cuentos. Buenos Aires: Centro Editor de América Latina, 1968, 136 p. Recoge: 17, 29 y 30.

35. Cuentos completos. Caracas: Monte Avila, 1968, 171 p. No recoge: 1, 2, 3, 4, 7 y 17.

36. Novelas corkas completas. Caracas: Monte Avila, 1968. 235 p. Recoge 19, 23, 24 y 27.

37. Las máscaras del amor. Buenos Aires: Centro Editor de América Latina, 1968, 102 p. Antología preparada por Emir Rodríguez Monegal.

38. Obras completas. México: Aguilar, 1970, 1431 p. Prólogo de Emir Rodríguez Monegal, pp. 9-44. No recoge: 1, 2, 3, 4, 7 y 9. 


\section{Fragmentos de Novelas}

39. "Tiempo de abrazar", Marcha, No. 189, 25 junio 1943, 2" sección, pp. 4-5. [Novela inédita].

40. "Excursión", Marcha, No. 176, 19 marzo 1943, p. 14. [Fragmento no recogido].

41. "Tiempo de abrazar", Marcba, No. 216, 31 diciembre 1943, pp. 18-19. [Novela inédita].

42. "Polvo enamorado", Marcha, No. 279, 27 abril 1945, p. 15. [Frag. mento de Para esta noche, pp. $72-74$ de la $1^{\text {a }}$ ed.].

43. "Nueve de. julio", Marcba, No. 314, 28 diciembre 1945, p. 14. [Aparece como fragmento de La cara de la desgracia, pero no fue incluido].

44. "Fragmento", Marcha, No. 440, 6 agosto 1948, p. 14. [Capítulo XXX de Tierra de nadie].

45. "El señor Albano", Número, año 1, No. 2 (mayo-julio 1949), pp. 91-109. [Ultimo capítulo de La vida breve].

46. "Naturaleza muerta", Asir (Mercedes, Uruguay), No. 21 (abril 1951). Introducción de Atturo Sergio Visca, pp. 41-42. [Capítulo VII de La vida breve].

47. "María Bonita", Marcha, No. 628, 27 junio 1952, p. 27. [Parte del primer capítulo de Juntacadáveres].

48. "Los adioses", Las ciento y una (Buenos Aires), Año 1, No. 1 junio 1953), p. 6 [pp. 22-26 de Los adioses].

49. "María Bonita", Agón (Montevideo), No. 1, (abril 1954), pp. 3 y 8. [Capitulo $\mathrm{V}$ de Juntacadáveres].

50. "La glorieta", Marcha, No. 845, 28 diciembre 1956, pp. 27-28. [Capitulo "La glorieta-I" de El astillero].

51. "El regalo", Entregas de la Licorne (Montevideo), No. 11, (1958), pp. 91-95. [Fragmento de El astillero, pp. 59-66].

52. "El entierro del chivo", Marcha, No. 797, 18 sept. 1959, 2: sección, Pp. 6 y 16. Presentado por T.J.D. [Fragmento de Una tumba sin nombre, pp. 13-22].

53. "La trampa", Marcha, No. 992, 31 diciembre 1959, 4a sección, pp. 8-9. [Presentado como capítulo de la novela El resto del invierno; es el capítulo "El astillero-II" de El astillero].

54. "Resoplando y lustroso", Marcha, No. 1139, $2^{\text {a }}$ sección, 28 dic. 1962, pp. 31-32. [Capítulos I y II de Juntacadáveres].

55. "Paseo", Puente (Montevideo), No. 1 (1963). Con introducción de Esteban Otero, p. 74. [Fragmento de Juntacadáveres]. 
56. "Mercado viejo", Acción, No. 6606, 10 diciembre 1967, p. 8. Presentado por D.T.F. [Capítulo de su última novela, aún inédita y sin título].

\section{TRADUCCIONES DE SUS OBRAS}

Inglés

57. "Jacob and the Other", en Prize Stories from Latin America; Winners of the Life en español Literary Contest. New York: Doubleday, 1963. Traducción de Izaak A. Langnas, pp. 307-345 de la edición de Dolphin Books, 1964. ["Jacob y el otro"].

58. "Welcome, Bob", Odyssey Review, Vol. 3, No. 2 (June 1963), pp. 192-99. Trad. de Hanna Edwards. ["Bienvenido, Bob"].

59. "Dreaded Hell", en J. M. Cohen, ed. Latin American Writing Today. Baltimore: Penguin Books, 1967, pp. 34-48.

60. The Shipyard. New York: Scribner's Sons, 1968, 190 p. Traducción de Rachel Caffyn. [El astillero].

61. "A Dream Realized" y "Welcome, Bob", en Carpentier, Hortense and Janet Brof, edls. Doors and Mirrors: Fiction and Poetry from Spanisb America. N. Y.: Grossman Publishers, 1972. ['Un sueño realizado" y "Bienvenido, Bob"]. Por aparecer.

\section{Italiano}

62. "L'inferno tanțo temuto", en Doménico Porzio, ed., Le più belle nouvelle di tutti i paesi. Milano: Aldo Martello Editore, 1966. ["El infierno tan temido"].

63. La vita breve. Milano: Feltrinelli Editore, 1970. 298 p. Traducción de Enrico Cicogna. [La vida breve].

64. Raccatactdaveri. Milano: Feltrinelli Editore, 1969. 274 p. Traducción de Enrico Cicogna. [Juntacadáveres].

\section{Francés}

65. Le Chantier. París: Editorial Stock, 1967. 209 p. Prefacio de MaxPol Fouchet, pp. 7-10. Traducción de Laure Guille-Bataillon. [El Astillero].

66. Trousse-Vioques. Paris: Editorial Stock, 1970. 290 pp. Traducción de Jean-Jacques Villard. [Juntacadáveres]. 
67. La vie brève. Paris: Stock, 1971. 347 pp. Trad. de Alice Gascar. Prefacio de Laure Guille-Bataillon. [La vida breve].

\section{Portugués}

68. Junta-Cadáveres. Rio de Janeiro: Civilização Brasileira, 1968. 238 p. Traducción de Flávio Moreira da Costa. [Juntacadáveres].

\section{Alemán}

69. "El infierno tan temido" y "Bienvenido, Bob" en José E. Friedl Zapata, ed. Das Haus in der Calle del Socorro und andere Erzäb. lungen aus Uruguay. Tübingen: Horst Erdmann Verlag, 1971. Traducción de Friedl Zapata.

\section{Artículos Periodísticos}

"Señal", Marcba, No. 1, 23 junio 1939, p. 2. [Sin firma].

"Una voz que no ha sonado", Marcba, No. 2, 30 junio 1939, p. 2. [Firmado: Uno].

"La piedra en el charco" [Reflexiones literarias publicadas en Marcha, con el seudónimo de Periquito el Aguador]. Números: 6 (28 julio 1939); 7 (4 agosto 1939); 9 (18 agosto 1939); 10 (25 agosto 1939); 11 (1 sept. 1939); 12 (8 sept. 1939); 19 (27 octubre 1939); 23 (24 nov. 1939); 26 (15 dic. 1939); 28 (30 dic. 1939); 75 (29 nov. 1940); 76 (6 dic. 1940); 77 (13 dic. 1940); 80 (10 enero 1941); 82 (31 enero 1941); 83 (7 febrero 1841).

Cartas humorísticas publicadas en Marcba, con la firma Grucho Marx. "Se regala una idea", No. 75 (29 nov. 1940); "Churchill-Marx", 76 (6 dic. 1940); "Como me lo contaron", 77 (13 dic. 1940); "Sin tema" 78 (20 dic. 1940); "La guerra permanente", 80 (10 enero 1941); "Carnaval sin César", 81 (24 enero 1941); "Ruderico I de Borgoña", 82 (31 enero 1941); "Autobrulote", 84 (14 feb. 1941); "Estilo gráfico", 85 (21 feb. 1941); "Ay de los tibios!", 86 (28 feb. 1941); "Llamado al pais", 87 (7 marzo 1941); "Se llama Andresillo", 88 (14 marzo 1941); "Dejad que los niños", 89 (21 marzo 1941); "Salud al primer cruzado", 90 (28 marzo 1941); "Xenofobia a mí?", 91 (4 abril 1941); "Inútil para sordos", 93 (25 abril 1941).

"[Graham] Greene visto por un lector", Letra y linea (Buenos Aires), 
octubre de 1953. Reproducción en Marcha, No. 700, 11 dic. 1953, p. 15.

"Literatura 1956: Sagan y M. Drouet", Acción, 21 diciembre 1956. [Firmado: D. G.].

"Nada más importante que el existencialismo", Acción, 22 octubre 1957;

p. 6. [Sobre Sartre y Camus]

“Otra vez 'Lolita', Marcha, No. 961, 29 mayo 1959, p. 20.

"Para Destouches, para Céline", Marcha, No. 1086, 1 dic. 1961, p. 31. [Necrológica a Céline, publicada sin firma].

"Y pensar que hace diez años...", Acción, 23 junio 1962, p. 8. [Sobre Carlos Gardel; en la misma página se reproduce el artículo "Gardel" de Julio Cortázar].

"Raúl Artagaveytia", Acción, 29 julio 1962, p. 5. [Véase en la misma página irónica carta de Onetti].

"Réquiem por Faulkner", Marcha, No. 1115, 13 julio 1962, p. 31.

"William Faulkner", Acción, 15 julio 1962, p. 5.

"Divagaciones para un secretario", Acción, 24 octubre 1963, p. 19. [Balance de los últimos quince años de literatura].

"Modesta contribución de Ahoraquimismo", Acción, 10 agosto 1964.

"Herman S. G., Hermano niño", Acción, 5 octubre 1964.

"Si hubiéramos ido", Acción, 31 diciembre 1965. [Sobre el tema: ¿Existe una cultura uruguaya?].

"Reflexiones literarias", Acción, 13 noviembre 1966. [Sobre la novelística contemporánea].

"Usted perdone, Guevara", Marcha, 11 octubre 1968, p. 31.

"Onetti explica a 'Periquito el Aguador"”, Capitulo Oriental (Montevideo), No. 30 (octubre 1968), p. 467.

\section{MisCeláNeA}

\section{Prólogos}

Arlt, Roberto. I sette pazzi. [Los siete locos]. Milano: Bompiani Editore, 1971. Prólogo de Onetti: "Semblanza de un genio rioplatense"; reproducido en Marcha, No. 1545, 28 mayo 1971, pp. 13 y 16; y en Macedonio, No. 11 (1971), pp. 49-58.

Denis Molina, Carlos. Lloverá siempre. Montevideo: Arca, 1967. Ptólogo de Onetti, pp. 7.8. 
Traducciones del inglés

Atwood Taylor, Phoebe. El misterio de Cabo Cod. [The Cape Cod Mistery]. Buenos Aires: Editorial Poseidón, 1946. [Trad. en colaboración con E. M. Pekelharing, sin la firma de Onetti].

Caldwell, Erskine. La verdadera tierra [This Very Earth] Buenos Aires: Editorial Schapire, 1954.

Drake, Burgess. Hijos del viento [Children of the Wind]. Buenos Aires: Ed. Acme, 1957.

Faulkner, William. "Todos los aviadores muertos". [All the Dead Pilots]. Marcba, No. 52, 21 junio 1940, pp. 20-21; y en el No. 53, 28 junio 1940, pp. 22-23. [Sin firma].

Wellman, Paul I. Los comancberos [The Comancberos]. Buenos Aires, 1956.

Disco

Juan Carlos Onetti. En la colección: Voz Viva de América Latina. Universidad Nacional Autónoma de México, 1967. Presentación de José Emilio Pacheco.

\section{ENTREvistas, Reportajes y ENCUESTAS}

Calm, Lilliam. "Conversando con J.C.O.", El Sur (Concepción), 7 septiembre 1969.

Castillo, Guido. "Ahora en Montevideo", El País, 28 enero 1962, p. 6

"Consulta al pueblo sobre el Frente Amplio", Marcha, No. 1527, 8 enero 1971, p. 6.

Cousté, Alberto. "Onetti: historia en dos ciudades", Primera Plana (Buenos Aires), 17 octubre 1967, pp. 52-54.

"De cómo J.C.O. y Carlos Martínez Moreno se entrevistaron mutuamente en el nido de Cormorán", Cormorán (Santiago de Chile), año 1, No. 7 (1970), pp. 8-11.

Díaz Sosa, Carlos. "Conversación con J.C.O.", Papel Literario de El Nacional (Caracas). 20 agosto 1967, p. 4.

"Doble cuestionario a J.C.O.", Marcha, No. 1513, 2 oct. 1970.

"Encuesta entre escritores nacionales", El Popular (Montevideo), 26 enero 1962.

"Encuesta literaria de Marcba", Marcba, No. 1010, 27 mayo 1960, p. 23. 
"Entrevista a J.C.O.", Imagen (Caracas), No. 6, (1/15 agosto 1967), pp. 3-4.

Galeano, Eduardo H. "Consagración de dos escritores. Onetti, el áspero. La simpatía de Paco [Espínola]", Marcha, No. 1091, 12 enero 1962, p. 11.

Gilio, María Esther. "Onetti y sus demonios interiores", Marcha, 1 julio 1966, pp. 24-25.

—. "Un monstruo sagrado y su cara de bondad", La Mañana (Montevideo), 20 agosto 1965. [Las dos entrevistas de M. E. Gilio fueton recogidas en: Protagonistas y sobreviventes. Montevideo: Arca, 1968].

Gutiérrez, Carlos María. "Onetti el escritor", Repórter (Montevideo), No. 25, 2 octubre 1961, pp. 27-29. [En Repórter, No. 27, 1 nov. 1961, se publica carta de Onetti ("Onetti no fue guerrero") en la cual pone en duda algunos datos de C.M.G.].

- "Onetti en el tiempo del cometa", Panorama (Buenos Aires), No. 144, 16 dic. 1969, pp. 47-49. [Sin firma].

G., J. "Siempre Onetti", Confirmado (Buenos Aires), 9 nov. 1967, pp. 49-50.

"J.C.O. Inocente del éxito", Ercilla, No. 1784, 29 agosto al 2 sept. 1969, pp. 91-92. [Cuestionario de Alfonso Calderón].

"Onetti por él mismo", La idea (Montevideo), 19 agosto 1971, p. 16. [Breve texto que será publicado en: Sara Facio y Alicia D'Amico, Retratos y atutorretratos, Buenos Aires: Sudamericana, 1972].

Rodríguez Monegal, Emir. "Conversación con Onetti", Eco, No 119, (marzo 1970), pp. 442-475.

Zitarrosa, Alfredo. "Onetti y la magia de El Mago [Gardel]", Marcha, No. 1260,25 junio $1965,2^{\text {a }}$ sección, pp. 1 y 6.

\section{CRÍtICA SOBRE LA OBRA DE ONETTI}

\section{Libros Tesis y Colecciones de Ensayos}

Aínsa, Fernando. Las trampas de Onetti. Montevideo: Alfa, 1970, $194 \mathrm{p}$.

Chrzanowski, Joseph A. Alienation in the Novels of Juan Carlos Onetti. Tesis doctoral inédita. Pennsylvania State University, 1971. 244 p. García Ramos, Reinaldo ed. Recopilación de textos sobre Juan Carlos Onetti. La Habana: Casa de las Américas, 1969, 197 p. [Contiene: Mario Benedetti, "J.C.O. y la aventura del hombre". José Pedro 
Diaz, "Tan triste como ella". "Entrevista a J.C.O.", Imagen. Jacques Fressard, "Onetti en Francia". Juan Carlos Ghiano, "J.C.O. y la novela". Maria Esther Gilio, "Un monstruo sagrado y su cara de bondad". Luis Harss, "J.C.O., o las sombras en la pared". Elisa Lerner, "Juntacad'áveres". Ricardo Latchan, "Una tumba sin nombre". Carlos Maggi, "Retrato de J.C.O.". Nelson Marra, "Santa María, ciudad-mito en la literatura de Onetti". Lucien Mercier, "J.C.O. en busca del infierno". Emir Rodríguez Monegal, " $\mathrm{La}$ fortuna de Onetti". Angel Rama, "Origen de un novelista y una generación literatia". Arturo Sergio Visca, "Trayectoria narrativa de Onetti"].

Giacoman, Helmy F. ed. Homenaje a Juan Carlos Onetti. New York: Las Americas Publ. Co. [en prensa].

Gómez Mango, Lídice ed. En torno a Juan Carlos Onetti. Notas criticas. Montevideo: Fundación de Cultura Universitaria, 1970. 105 p. [Contiene: Rubén Cotelo, "Realidad y creación en Una tumba sin nombre", "El guardián de su hermano", "Muchacha y mujer", "Humor y desesperación en J.C.O.", "Arquetipo de la pareja viril". Lucien Mercier, "J.C.O. en busca del infierno". José Pedro Díaz, "De su mejor narrativa", "El ciclo onírico". Guido Castillo, "Muerte y salvación en Santa Maria". Y dos ensayos inéditos: Esteban Otero, "La obra de J.C.O. Temática y evolución". Gabriel Saad, "Jacob y el otro o las señales de la victoria"].

Haldeman, Gary A. Juan Carlos Unetti y la evasión de la realidad. Tesis inédita. ("Masters") University of Oklahoma, 1970. 86 p.

Jones, Yvonne Perier. Form and Content in Juan Carlos Onetti's El astillero. Tesis inédita. University of Washington, (Seattle), 1966, $64 \mathrm{p}$.

Jones, Yvonne Perier. The Formal Expression of Meaning in Juan Carlos Unetti's Narrative Art. Tesis doctoral. Univ. of Washington, Seattle, 1970. 145 p. [Publicada en México: CIDOC, 1971. Prefacio de Luis Alfonso Díez].

\section{ESTUdios Notas y ReseÑas}

Abbate, Michele. "Il fosco Onetti", Gazzetta del Mezzogiorno (Bari), 8 ottobre 1969. [Sobre Juntacadaveres].

Aínsa, Fernando. "Los mecanismos de evasión en la obra de J.C.O.", Amaru, No. 12 (junio 1970), pp. 82-88. [Recogido en su libro]. . "Onetti: un 'outsider' resignado", Cuadernos hispanoamericanos, No. 243 (marzo 1970), pp. 612-38. [Recogido en su libro]. 
Alegría, Fernando. Historia de la novela bispanoamericana. $3^{\text {a }}$ ed., México: Ediciones de Andrea, 1966, pp. 231-33.

Alvarez, José Carlos. "Pervivencia de un relato", La Mañana, 20 agosto 1965, p. 10. [Sobre El pozo].

Alvarez Palacio, Fernando. "Juntacadáveres. Descubrimiento de J.C.O.", El Correo de Andalucía (España), 19 junio 1970.

Alsina Thevenet, Homero, et al. "El pozo, de J.C.O. Veinticinco años después", Marcba, No. 1255, 21 mayo 1965, p. 16.

Alsina Thevenet, Homero. "Un nuevo libro: Tierra de nadie por J.C.O.", Cine Radio Actualidad (Montevideo-Buenos Aires), No. 267, 25 julio 1941, sin numerar [18-19].

-. "Una novela uruguaya. J.C.O. La vida breve", Marcba, No. 590, 24 agosto 1951, p. 14-15.

Anderson Imbert, Enrique. Historia de la literatura bispanoamericana. $5^{a}$ ed., Vol. II, México: Fondo de Cultura Económica, 1966, pp. 276-78.

Anónimo. "Cuentos completos", La Nación, 22 octubre 1967.

-. "Cuensos completos por J.C.O.", Confirmado (Buenos Aires), 13 febrero 1969, p. 45.

—. "El nacimiento de la odisea", Primera Plana, 15 junio 1965, pp. 75-76. [Sobre El pozo].

-. "Esplode l'Uruguay", L'espresso (Roma), 7 sept. 1969. [Sobre Juniacadaveres].

—. "J.C.O. La vita breve", Gazzeta di Mantova (Mantova), 6 feb. 1971.

-. "Juntacadáveres", S. P. (Madrid), 14 junio 1970.

-.. "Juntacadáveres", Revista Meridiano (Madrid), junio de 1970.

-. "La fortuna de Onetti", Mundo nuevo, No. 24 (junio de 1968), p. 95.

-2. "La novia sin novio", Acción, 28 abril 1968.

—. "La vita breve di J.C.O.", L'espresso (Roma), 17 gennaio 1971.

—. "Las palabras del amor", Análisis (Buenos Aires), 4/10 agosto 1970. [Sobre Juntacadáveres].

-. "El acabóse: Juntacadáveres por J.C.O.", Primera Plana No. 120, 23 febrero 1965, sin numarar [44 y 46]. Reproducido con el título "Onetti en la Argentina", en Acción, 14 marzo 1965.

-.. "Onetti: triste, fané y descangayado", Semana (Caracas), 5/12 diciembre 1968, p. 28. [Sobre Cuentos completos].

- "Prosa convincente y cabal arquitectura de un relato", Clarin, 14 septiembre $1967,4^{\text {a }}$ sección, p. 2. [Cuentos completos]. 
—. "Raccattacadaveri quasi paradosso", L'adige (Trento), 7 ottobre 1969.

- "Soledad en los espejos", Panorama, 4 febrero 1969. [Sobre No. velas cortas completas].

- "The Santa María saga", The Times Literary Supplement, No. 3591 (25 December 1970), p. 1509. [Reseña de Iuntacadáveres y de Las trampas de Onetti de Aínsa].

-.. "The Shipyard", Kirkus Reviews, Vol. 36 (1 March 1968), pp. 288-89.

- "Tierra de nadie por J . C. Onetti", La Nación, $2^{\mathrm{a}} \mathrm{sec}$., 13 julio 1941, p. 5.

-. "Un grande scrittore sudamericano. Onetti: La vita breve", L'Arena (Verona), 28 gennaio 1971.

Antonelli, Edilio. "Raccattacadaveri de J.C.O. Frugando nel fondo di una città uruguaiana", Stampe Sera (Torino), 26 settembre 1969.

Argo. "J.C.O.: La vita breve", Il Mattino (Napoli), 11 febbraio 1971.

B., E. "J.C.O.: Raccattacadaveri", Il Secolo XIX (Genova), 1 ottobre 1969.

B., Ph. "Le Chantier", Nouvelles Littéraires (Paris), 2 novembre 1967. p. 4. [El astillero].

Barisani, Blas. "El realismo materialista de J.C.O.", Cuadernos del Sur Buenos Aires), Año 6, No. 63 (octubre 1969), pp. 853-54.

Bejarano, Mariano. "Onetti: la identidad perdida", Suplemento de Imagen, No. 65, 15/31 enero 1970, sin numerar [seis páginas].

Beltrán Guerrero, Luis. "Juntacadáveres", El Universal, 14 sept. 1967, p. 4.

Benedetti, Mario. "Prólogo" a Un sueño realizado y otros cuentos. Montevideo: Número, 1951, pp. 7-14.

- . "La aventura del hombre. Culmina con su reciente novela la obra literaria de J.C.O.", La Mañana, 26, 27 y 28 de octubre de 1961. [Sobre El astillero].

—_. "Brinda en sus cuentos J.C.O. una concentrada versión de la soledad del hombre", La Mañana, 14 y 15 de noviembre de 1962.

_-. "J.C.O. y la aventura del hombre", Literatura uruguaya del siglo XX. Montevideo: Alfa, 1963, pp. 76-95. También en: Puente, No. 1 (otoño 1963), pp. 133-145.

- . "Juntacadáveres: una nueva apertura", La Mañana, 20 agosto 1965, p. 10. Reproducido en: Casa de las Américas, No. 39 (1966), pp. 143-145.

-. "J.C.O. y la aventura del hombre", "La cultura en México", su- 
plemento de Siempre!, No. 342, 4 septiembre 1968, pp. 2-6. [Artículo definitivo]. Lo vuelve a publicar (parcialmente) como prólogo de la edición cubana de $E l$ astillero; en la $2^{\text {a }}$ ed. (1969) de Literatura uruguaya del siglo $\mathrm{XX}$; y en Angel Flores y Raúl Silva Cáceres, eds. La novela bispanoamericana ackual. New York: Las Américas, 1971, pp. 73-90.

Bevilacqua, Alberto. "L'uruguaiano maledetto", Oggi (Milano), 29 ottobre 1969, p. 155. [Sobre Juntacadáveres].

Bianchini, Angela. "Il romanzo sudamericano alla scoperta delle città. Un' opera suggestiva dell' uruguaiano J.C.O.", La Stampa (Torino), 19 ottobre 1969. [Sobre Juntacadaveres].

Bianchini, Angela. "La 'nera concentrazione' di Onetti. La vita breve", La Stampa (Torino), 31 diciembre 1970.

Blanco Amor, José. "Revaloración de Onetti", La Nación, 3" sec., 9 febrero 1969, p. 3.

Blengino, Vanni. "Il Mondo di Onetti", Rinascita (Roma), 30 gennaio 1970.

Bollo, Sarah. Literatura uruguaya 1807-1965. Tomo II, Montevideo: Ediciones Orfeo, 1965, pp. 151-53.

Bonnefoy, Claude. "Une ville toute rouillée", Le Nouvel Observateur (Paris), 13 décembre 1967. [Sobre El astillero].

Bonura, Giuseppe. "Incontro con lo scrittore J.C.O. Tutti noi conosciamo la città que non c'è", Avvenire (Bologna), 1 ottobre 1969. [Sobre Juntacadáveres].

Bordelois, Yvonne A. "J. C. Onetti. Tan triste como ella", Cuadernos (Paris), No. 98, 1965, pp. 85-86.

Bosco, María Angélica. "El astillero", Ficción, No. 33-34, (Sept.-Dic. 1961), p. 202.

Briante, Miguel. "Onetti o el ritual de la maestria", Confirmado, 3 octubre 1968, p. 52. [Sobre Novelas cortas completas].

Brushwood, John S. "To Play the Game is to Live", The Kansas City Star, 8 June 1968, p. 8D. Reproducida en: Review '68 (1969), pp. 60-61. [Reseña de El astillero].

Bueno, Salvador. "Juntacadáveres", Sin nombre, No. 3 (1971), pp. 90.93.

- "Iuntacadáveres ¿Novela social?", Indice, 1-15 febrero 1971, pp. 61-62.

Cano Gaviria, Ricardo. "De Brausen a Onetti", Cuadernos para el didlogo (Madrid), No. 69 (junio 1969), pp. 43-44.

Campos, Jorge. "J. C. Onetti y su Juntacadáneres", Insula, No. 286, septiembre 1970 , p. 11. 
-... "Los mundos de Onetti', Insula, No. 299, octubre 1971, p. 11. [Sobre las Obras completas].

Carney, Edmund J. The Short Novel in Contemporary Latin American Literatupe. Tesis doctoral inédita. University of Illinois, 1971. [Sobre La cara de la desgracia, pp. 121-28].

Carrillo, Bert B. The Alienated Hero in Four Contemporary Spanish American Novels. Tesis doctoral inédita. University of Arizona, 1970. [Sobre El astillero, pp. 48-81].

Cartarón, Luciano. "J.C.O.", Región (Oviedo), 7 junio 1970. [Sobre Juntacadáveres].

Casey, Calvert. "J.C.O. y El astillero", Casa de las Américas, No. 26 (octubre-noviembre 1964), pp. 117-119.

Castellanos, Rosario. "Una proposición. Cuentos completos por J.C.O.", Visión (México), 14 marzo 1969, p. 55.

Castiel, Dionisio. "Onetti: Juntacadáveres", Hispania, Vol. 54, No. 1 (March 1971), pp. 209-10.

Castillo, Guido. "Muerte y salvación en Santa María", El Pais, 28 enero 1962, p. 6. [Sobre El astillero].

Concha, Jaime. "Conciencia y subjetividad en El pozo", Estudios Filológicos de la Universidad Austral de Cbile (Valdivia), No. 5 (1969), pp. 197.228.

- "J.C.O.: El pozo", Anales de la Universidad de Cbile, Año CXXIV, No. 139 (julio-sept. 1966), pp. 238-39.

- "J.C.O.: Para esta nocbe", Anales de la Universidad de Cbile, Año CXXIV, No. 140 (octubre-dic. 1966), pp. 248-52.

—. "Sobre Tierra de nadie, de J.C.O.", Atenea, No. 417 (julio-sept. 1967), pp. 173-97.

—. "Un tema de J. C. O.", Revista Iberoamericana, No. 68 (mayoagosto 1969), pp. 351-63.

Cordelli, Franco. "Raccattacadaveri di Onetti", Avanti (Roma/Milano), 4 ottobre 1969.

Cornejo Polar, Jorge. "El astillero o la desesperanza total", Eco (Arequipa), 6 abril 1969.

Cotelo, Rubén. "Arquetipo de la pareja viril", El País, 14 agosto 1966. [Sobre Jacob y el otro].

—_. "El guardián de su hermano", El Pais, 12 diciembre 1960. [Sobre La cara de la desgracia].

-. "El pozo, justo ahora", El País, 29 agosto 1965, p. 8.

—. "Humor y desesperación en J.C.O.", El País, 27 agosto 1962. [Sobre El infierno temido]. 
- . "Muchacha y mujer", El Pais, 16 febrero 1964. [Sobre Tan triste como ella].

—. "Realidad y creación en la última novela de Onetti", El País, 18 octubre 1959. [Sobre Una tumba sin nombre].

Cresta de Leguizamón, María Luisa. "Una novela uruguaya", Libros Selectas (México), No. 24 (15 enero 1965), pp. 13-20. [Sobre La cara de la desgracia].

Darino, Eduardo. "El submundo existencial", Comentarios Bibliográficos Americanos (Montevideo), Vol. II, No. 9 (sept-octubre 1970), pp. 25-26.

Dávalos, Baica. "La ciudad creada en el peligro. Juntacadáveres", Zona Franca (Caracas), Año III, No. 44 (abril 1967), pp. 51-53.

Deredita, John. "Fernando Aínsa. Las trampas de Onetti", Books Abroad, Vol. 45, No. 3 (Summer 1971), p. 482. [Reseña].

- "The Shorter Works of J.C.O.", Studies in Short Fiction, Vol. VIII, No. 1, (Winter 1971), pp. 112-22.

Onetti", Revista Iberoamericana, No. $76-77$ (juliodic. 1971), pp. 651-665.

Díaz, José Pedro. "De su mejor narrativa", Marcha, 14 oct. 1960, p. 23. [Sobre La cara de la desgracia].

-. "J.C.O. Un ciclo onírico", Marcha, No. 1077, 29 septiembre 1961, p. 21. [Sobre El astillero].

- "Otros prosistas de hoy", Marcha, No. 1196, 6 marzo 1964, p. 28. [Sobre Tan triste como ella].

Diez, Luis Alfonso. "Aproximación a J.C.O.", Revista de Occidente, No. 93 (diciembre 1970), pp. 367-378.

." 'La novia robada', relato inédito de J.C.O.", Nueva narrativa bispanoamericana, Vol. 1, No. 2, (Septiembre 1971), pp. 185-195.

-. "Onetti: revaloración de un gran novelista", El Norte de Castilla, 3 enero 1971, p. 17.

Donoso, José. Prólogo a El astillero. Madrid: Salvat Editores con la colaboración de Alianza Editorial, 1970, pp. 11-15.

Donoso Pareja, Miguel. "Juntacadáveres", El Día (México), 12 abril 1967.

Dufour, Jean-Marc. "Trousse-Vioques par J.C.O.", Nouvelles littéraires, 27 Août 1970, p. 5. [Juntacadáveres].

Englekirk, John E. and Margaret M. Ramos. La narrativa uruguaya. Estudio crítico-bibliográfico. Berkeley and Los Angeles: University of California Press, 1967, pp. 93-94 y 225-26. 
Eyzaguirre, Luis Bernardo. El héroe en la novela hispanoamericana del siglo XX. Tesis doctoral inédita, Yale University, 1970. [El astillero, pp. 396-398].

-C. "Rayuela, Sobre héroes y tumbas y El astillero: Búsqueda de la. identidad individual en la novela hispanoamericana contemporánea", Nueva narrativa bispanoamericana, Vol. II, No. 2 (septiembre 1972), pp. 101-18.

Fell, Claude. "Le monde turbulent d'Onetti", Le Monde, 17 décembre1971, p. 18. [Sobre La vida breve].

Figueira, Gastón, "J.C.O.: Tierra de nodie", Books Abroad, Vol. 17, No. 3 (Summer 1943), pp. 265.266.

Flores, Angel ed. The Literature of Spanish America. Vol. VI, New York: Las Americas Publishing Co., 1967, pp. 259-60.

Forastieri Braschi, Eduardo. "J.C.O. y la perfecta imperfección", Sin nombre, Vol. II, No. 2 (1971), pp. 72-81. [Sobre "La casa en la arena"].

Foster, David William. "Cuentos completos", Books Abrodd, Vol. 42, No. 2 (Spring 1968), pp. 244.45.

Franco, Jean. An Introduction to Spanish-American Literature. Cambridge, England: The University Press, 1969, p. 310 y pp. 330-332.

- The Modern Culture of Latin America. Society and the Artist. New York: Frederick A. Praeger Publ., 1967, pp. 200 y 245-46.

Fressard, Jacques. "La vie comme un songe", La Quinzaine Littéraire, $1 / 15$ novembre 1967 , p. 14 . [Sobre El astillero]. Reproducido en Marcha, No. 1381, 1 dic. 1967, p. 29, con el título: "Onetti en Francia".

Fuente, Albert de la. "La estructura de la novela de J.C.O.: Juntacadáveres", Revista iberoamericana, No. 79 (abril-junio de 1972), pp. 263.77.

Gallagher, David. "The Exact Shade of Gray", The New York Times Book Review, 16 June 1968, pp. 4-5. Recogido en: Review '68, (1969), pp. 58-60. [Sobre El astillero].

Gasca, Argelio. "Breves y harapientas notas sobre J.C.O.", Diorama de la Cultura, Suplemento de Excélsior (México), 23 agosto 1970.

Gertel, Zunilda. La novela bispanoamericana contemporánea. Buenos Aires: Editorial Columba, 1970, pp. 83-88. [Sobre El pozo].

Ghiano, Juan Carlos. "El mundo narrativo de Onetti", La Nación, 11 abril 1971, $3^{\text {a }}$ sección, p. 2. [Sobre las Obras completas].

-. "Los adioses", Oeste, año X, No. 18-20 (enero-marzo 1955), pp. 37.38 . 
-. "Juan Carlos Onetti y la novela", Ficción, No. 5 (1957), pp. 247.253.

Goodsell, James Nelson. "Symbolic Figures in an Empty Landscape. The Shipyard by J.C.O.", Christian Science Monitor, Vol. 60, 8 October 1968, p. CI.

Grande, Félix. "J.C.O. y una escenografía de obsesiones", Cuadernos bispanoamericanos, No. 234 (junio 1969), pp. 710-720. [Sobre La vida breve].

Gravina, Alfredo. "J.C.O. Los adioses", La Mañana, 14 enero 1971.

G., L. [Luis Gregorich]. "La vida breve", Diccionario de la literatura universal (Bajo la dirección de Roger Pla). Buenos Aires, Muchnik Editores, 1966, p. 439.

Guille-Bataillon, Laure. "La vie brève: piedra angular de la literatura", Marcha, 7 abril 1972, p. 31. [Trad. del prólogo de la edición francesa de La vida breve].

Guillén Tapia, Orlando. "J.C.O.: Tierra de nadie", La palabra y el hombre (México), No. 45 (enero-marzo 1968), pp. 197-98.

Harss, Luis y Barbara Dohmann. Los nuestros. Buenos Aires: Sudame. ricana, 1966, pp. 214-251. En inglés: Into the Mainstream. Conversations with Latin-American Writers. N. Y.: Harper and Row, 1967, pp. 173-205.

Hernández, Caracé. "J.C.O.: pistas para sus laberintos", Mundo Nuevo, No. 34 (abril 1969), pp. 65-72.

Hierro Gambardella, Luis. "Un mundo de sombras y penumbras", Acción, 10 septiembre 1961. [Sobre El astillero].

Irby, James E. "Aspectos formales de La vida breve de J.C.O.", en Carlos H. Magis, ed., Actas del Tercer Congreso Internacional de Hispanistas. México: El Colegio de México, 1970, pp. 453-460.

- La influencia de William Faulkner en cuatro narradores bispanoamericanos. México: edición mimeográfica, 1956, pp. 75-109. Reproducido (parcialmente) con el título " $\mathrm{La}$ influencia de William Faulkner en Onetti", Marcha, No. 890, 29 noviembre 1957, pp. 28-29.

L., M. A. [Mario A. Lancelotti] "El astillero", Sur, No. 275 (marzoabril 1962), pp. 101-02.

Ladeveze. "Expresión y lenguaje en J.C.O.", Nuevo diario (España), 10 mayo 1970. [Sobre Juntacadaveres].

Iatchan, Ricardo A. Antologia del cuento bispanoamericano contemporáneo. Santiago: Zig Zag, 1958, pp. 56.57 y 428.

-.. "Una tumba sin nombre", La Nación (Santiago de Chile), 4 
octubre 1959. Reproducido en El País, 8 noviembre 1959, con el título "El libro de J.C.O.". Incorporado a Carnet crítico. Montevideo: Alfa, 1962, pp. 123-28. Véase también en el mismo libro las pp. 117-22 (Un sueño realizado y otros cuentos), y las pp. 167-68 (La cara de la desgracia).

Laurenzi, Livio. "J.C.O. Raccattacadaveri", Il Ragguaclio librario (Milano), dicembre 1969.

Leal, Luis. Breve bistoria de la literatura hispanoamericana. N. Y.: Alfred A. Knopf, 1971, pp. 279-80 y 328-29.

- Historia del cuento bispanoamericano. México: Ediciones de Andrea, 1966, p. 126.

Lerner, Elisa. "Juntacadáveres", Revista Nacional de Cultura, No. 180 (abril-mayo-junio 1967), pp. 87-89.

López Rubio, Juvenal. "Onetti, un novelista del sino", Imagen, No. 35, 15/30 octubre 1968, p. 4. [Sobre Las novelas cortas completas].

Loza Aguerrebere, Rubén: Rómulo Cosse: Argimiro Beovide. "A treinta años de El pozo", La Unión (Minas, Uruguay), 14 oct. 1969.

Luchting, Wolfgang A. "Lectura critica de Los adioses. El lector como protagonista de la novela", Marcha, No. 1497, 12 junio 1970, pp. 14-15. Reproducido en: Proceedings: Pacific Northwest Conference of Foreign Languages, XXI (1970), pp. 178-86. En la cuarta edición de Los adioses (Montevideo, Arca, 1970), y en Nueva narrativa bispanoamericana, Vol. 1, No. 2 (septiembre 1971), pp. 175-184.

Luzi, Mario. "L'asceta del peccato", Corriere della Sera (Milano), 9 novembre 1969. [Sobre Juntacadaveres].

- _. "Onetti e i" boom" dei sudamericani. Eterno presente", Corriere della Sera, 21 gennaio 1971. [Sobre La vida breve].

M., C. "Obras completas de J.C.O.", El cronista comercial (Buenos Aires), 23 diciembre 1970.

M., F. "J.C.O.: La vita breve", Giornale di Vicenze (Vicenza), 3 dicembre 1970.

M., T. E. [Tomás Eloy Martínez]. "El jardín de las desdichas. Onetti: Cuentos completos", Primera Plana, 17 octubre 1967, pp. 54-55.

Machado, Alvaro Manuel. "Onetti l'homme sans qualités", Magazine Litteraire, September 1970, p 43. [Sobre Juntacadáveres].

Magallanes, Juan Mario. "Sobre el concurso de novela", Marcba, No. 88, 14 marzo 1941, p. 5. [Sobre Tiempo de abrazar, novela inédita]. Maggi, Carlos. "Retrato de J.C.O.", Marcha, No. 1070, 11 agosto 
1961, p. 28. Reproducido en: Gardel, Onetti y algo más. Montevideo: Alfa, 1964, pp. 84-88.

Mallea Abarca, Enrique. "Dos novelistas jóvenes", Nosotros, año 6, No. 66 (1941), pp. 307-317. [Sobre Bernardo Verbitsky y Tierra de nadie de Onetti, pp. 313-317].

Mamerem, Gerardus van. "La vida breve", La Gaceta ('Tucumán), 29 diciembre 1969.

Marra, Nelson. "Santa María, ciudad-mito, en la literatura de Onetti", Temas (Montevideo), No. 6 (abril-mayo 1966), pp. 32-34.

Martínez Carril, M. "Onetti, acaso la liberación", La Mañana, 12 abril 1966.

Martínez Moreno, Carlos. "Una novela rioplatense. Tierra de nodie de J.C.O.", Alfar (Montevideo), No. 80, año XX (1942), sin numerar [pp. 49-52].

Martini, Juan Carlos. "J.C.O. o escribir en Latinoamérica", Macedonio (Buenos Aires), No. 8 (primavera 1970), pp. 33-36.

Mercier, Lucien. "J.C.O. en busca del infierno", Marcba, No. 1129, 29 nov. 1962, pp. 30-31. [Sobre El infierno tan temido].

Mondéjar, Publio L. "J.C.O. o la salvación por la literatura", Artes $y$ Letras (España), No. 12, 29 agosto 1970, p. 10.

Morick. "Il pelo nell'uovo", Il Mattino (Napoli), 29 gennaio 1970. [Sobre Juntacadáveres].

Ortega, Julio. "Modernidad narrativa", Nueva Narrativa Hispanoamericana, Vol. II, No. 1 (enero 1972), pp. 205-07. [Reseña de las Obras completas].

Otero, Esteban. "Culminación de un narrador", Marcha, No. 990, 18 dic. 1959, p. 30 [Sobre Una tumba sin nombre].

Oviedo, José Miguel. "J.C.O.: una sórdida inmersión en el mal", Suplemento dominical de El Comercio, 8 mayo 1966. Reproducido en Hechos (Montevideo), 24 dic. 1966. [Juntacadáveres].

-.. "Onetti, Maestro del cuento", Suplemento dominical de El Comercio (Lima), 14 dic. 1969. [Sobre Cuentos completos].

P., O. "Cuentos completos", La Prensa, 27 abril 1969.

P. G., O. [Omar Prego Gadea]. "Onetti y su clave", El Diario (Montevideo), 15 agosto 1965, p. 3.

Pacheco, José Emilio. "Presentación" al disco dedicado a Onetti, Colección "Voz Viva de América", Universidad Nacional Autónoma de México, 1967, pp. 1-5.

Palacios, Antonia. "J.C.O.: Los adioses", Imagen, No. 2, 1967, p. 19. Pollmann, Leo. Der Neue Roman in Frankreich und Lateinamerika. 
Stuttgart: W. Kohlhammer Verlag, 1968, pp. 58-63 y 94-98. Trad. española: La nueva novela en Francia y en lberoamérica. Madrid: Gredos, 1971, esp. pp. 83.89 y $133-36$

Prego Gadea, Omar. "J.C.O., un solitario", Tribuna (Montevideo), Año 1, No. 11, 18 octubre 1959.

Prior, Aldo. "Los adioses", Sur, No. 230 (sept-oct. 1954), pp. 110-111. Puccini Darío. "Raccattacadaveri. Amaro e ambiguo il libro di Onetti", Parese Sera (Roma), 23 gennaio 1970.

R., M. "Ritorno al naturalismo simbolico in un'opera del paraguaiano (sic!) J.C.O., Raccattacadaveri", L'Unita (Roma), 1 ottobre 1969.

Rama, Angel. "El largo viaje de J.C.O.", Marcha, No. 1073, 1 sept. 1961, pp. 22-23. [Sobre El astillero].

—- "Juntacadáveyes de Onetti. Con sus mejores páginas", Marcba, No. 1251, 23 abril 1965, p. 31.

- - "Lo que va de ayer a hoy", Marcha, No. 1220, $2^{\text {a }}$ sección, 28 agosto 1964, pp. 2-9. Especialmente "Historia del año 1939", pp. 5.6 .

- "Origen de un novelista y de una generación literaria", en: $E l$ pozo, 2: ed. Montevideo: Arca, 1965, pp. 57-111.

- "Testimonio, confesión y enjuiciamiento de 20 años de historia literaria y de nueva literatura uruguaya", Marcba, No. 966, 3 julio 1959, p. B-18.

- Gonzalo de Freitas y Mario Trajtenberg, "Los premios literarios 1960", Marcba, No. 1083, 10 "noviembre 1961, p. 29 [Sobre $L a$ cara de la desgracia].

Rodríguez Monegal, Emir. "Para esta nocbe", Marcba, No. 222, 18 febrero 1944 , p. 14.

—. "J.C.O. y la novela rioplatense", Nímero, año 3, No. 13-14 (marzo-junio 1951), pp. 175-188. [Sobre La vida breve].

—. "Los cuentos de Onetti", Marcha, No. 646, 7 nov. 1952, p. 14. [Sobre Un sueño realizado].

—. "Una o dos historias de amor. Los adioses por J.C.O.", Marcha, No. 744, 10 diciembre 1954, pp. 14-15. También en: Nimero, año 6, No. 26 (marzo 1955), pp. 107-109.

- . "El astillero, fragmento de un mundo propio", Repórter (Montevideo), No. 25, 2 octubre 1961, p. 30.

- Narradores de esta América. Montevideo: Alfa, s.f. [1962], pp. 155-188. Recoge artículos anteriores.

_-. "Los psicodramas de J.C.O.", El País, 7 enero 1963, p. 7. [Sobre Los cuentos]. 
—. "La fortuna de Onetti", El País, 6 septiembre 1964.

-. "Una forma del fragmentarismo", El Pais, 16 mayo 1965. [Sobre Juntacadáveres].

- Literatura uruguaya del medio siglo. Montevideo: Alfa, 1966, pp. 221-260. [Reproduce ensayo incluido en Narradores de esta América y agrega "La fortuna de Onetti"].

—. "Onetti, tierra aún incógnita", Papeles (Caracas), No. 5 (novdic. 1967), pp. 23-29. Reproducido en Temas, No. 15, (enero-feb.marzo 1968), pp. 18-22, con el título "Anacronismo de Onetti". - . "Onetti o el descubrimiento de la ciudad", Capitulo Oriental, No. 28 (1968), pp. 433-447. [Refundición de artículos anteriores.].

—. "Prólogo" a Obras completas de J.C.O. México: Aguilar, 1970, pp. 9-41. [Nueva refundición].

Ruffinelli, Jorge: "Onetti en cuatro tiempos", Marcha, 18 diciembre 1970, p. 23.

Saad, Gabriel. "Prólogo" a Jacob y el otro. Un sueño realizado y otros cuentos. Montevideo: Ediciones de la Banda Oriental, 1965, pp. 7-14.

Sánchez, Luis A. Proceso y contenido de la novela bispanoamericana. $2^{*}$ ed. Madrid: Gredos, 1968, pp. 258-59, 543.

Sánchez Cortés, Diego. "Verbitsky, Onetti: el hombre urbano, el hombre universal", Contorno, No. 5/6 (sept. 1955), pp. 35-36.

Sánchez Riva, Arturo. "El concurso 'Ricardo Güiraldes': Tierra de nadie por J.C.O.", en De bombres y libros. Buenos Aires: Editorial Futuro, 1966, pp. 22-23.

Silva, Clara. "Media vuelta de tuerca. Los adioses", El País, 13 Dic. 1970, p. 2.

Solero, F. J. "J.C.O., La vida breve", Sur, No. 199 (junio 1951), pp. 69-71.

Sosnowski, Saúl. "The Shipyard by Onetti", Best Sellers (Univ. of Scranton, Pa.), Vol. 28 (1 June 1968), pp. 103-04.

Soto Aparicio, Fernando. "Realidad extraña", El Espectador (Bogotá), 15 agosto 1970. [Sobre Juntacadáveres].

Suárez Alba, Alberto. "Juntacadáveres: Onetti completa su trilogia", Norte Expres (Vitoria, España), 26 junio 1970.

T. F., D. [Danubio Torres Fierro]. "Onetti en Aguilar", La Mañana, 22 octubre 1970.

T., M. "Onetti: un sueño realizado", Confirmado, 15 junio 1967, pp. 66-68. [Sobre Tierra de nadie, ]acob y el otro y Un sueño realizado]. Thompson, Laurence S. "Onetti. The Shipyard", Library Journal, Vol. 93 (August 1968), p. 2898. 
Trillo Pays, Dionisio. "Tierra de nadie de J.C.O.", Marcba, No. 109, 15 agosto 1941, p. 2.

Umbral, Francisco. "Juan Carlos Onetti", Ya (Madrid), 13 junio 1970. [Sobre Juntacadáveres].

Vanasco, Alberto. "En torno a Los adioses", La Gaceta (Tucumán), 19 octubre 1954.

Vadercammen, Edmond. "Le Chantiep", Le Soir, 23 feb. 1967.

Vargas Llosa, Mario. "Primitives and Creators", The Times Literary Supplement, No. 3,481, 14 Nov. 1968, pp. 1287-88. Reproducido en Marcha, 10 y 17 de enero de 1969, con el título, "Novela primitiva y novela de creación en América Latina". También en la Revista de la Universidad de México, No. 10 (junio 1969), pp. 29-36.

Verani, Hugo J. "En torno a Los adioses de J.C.O.", Anales de la Universidad de Chile, No. 145 (1968), pp. 35.57.

- "Los comienzos: tres cuentos de Onetti anteriores a $E l$ p.ozo", Hispamérica (por aparecer): será reproducido en Eco (Colombia), número dedicado a Onetti.

Vigorelli, Giancarlo. "L'antico sorriso di J.C.O.", Il Tempo (Roma), ottobre 1969, p. 96.

Visca, Arturo Sergio. "Trayectoria narrativa de Onetti", en Antologia del cuento uruguayo contemporáneo. Montevideo: Universidad de la República, 1962, pp. 243-248.

—. "Desarraigo", El País, 29 sept. 1963. [Sobre El pozo].

—. "La novela como pesadilla", El País, 24 octubre 1971, p. 3. [Sobre Para esta noche].

- "Los que encendieron las lámparas. Felisberto [Hernández], Onetti, Morosoli", Suplemento "Ars" de El País, 27 marzo 1971, pp. 2-3. [Sobre El Pozo].

- "Onetti, 'Jacob y el otro" ", El Pais, 3 y 10 de diciembre de 1967.

—. "Panorama de la actual narrativa uruguaya", Ficción. No. 5 (1957), pp. 120-26.

—_. "Soledades rioplatenses", Asir (Mercedes, Uruguay), No. 36 (octubre 1954), pp. 21.29. [Sobre El Pozo].

Vitale, Ida. "Cuando los premios unen", Marcha, No. 1091, 12 enero 1962, p. 30.

_- "J.C.O.: El infierno tan temido. Dos cuentos rigurosos", Epoca, (Montevideo), 2 septiembre 1962. 
Wäber, Gottfried. "J.C.O., La vida breve", Iberoromania (München), Vol. 2, No. 2 (1970), pp. 134-149.

Walker, John. "Fernando Aínsa: Las trampas de Onetti", Hispania, Vol. 54, No. 4 (December 1971), pp. 976-77.

Webb, Kenneth. "Los adioses", Books Abroad, Vol. XXIX, No. 2, (Spring 1955), p. 212.

Wieck, Carl. "Deterioration of a Man", The Courier (Louisville), 15 September 1968. [Sobre $E l$ astillero].

Yankas, Lautaro. "Valores de la narrativa hispanoamericana actual", Cuadernos hispanoamericanos, No. 236 (agosto 1969), pp. 334-379. [Sobre El astillero].

Zum Felde, Alberto. "Aparición de J. C. Onetti", Marcha, No. 997, 12 febrero 1960, p. 23. [Sobre El pozo].

- Indice critico de la literatura bispanoamericana. La narrativa. Vol. II, México: Guaranía, 1959, pp. 463-68. Una versión más breve en: La narrativa en Hispanoamérica. Madrid: Aguilar, 1964, pp. 347.53 .

\section{MenCIONES Breves}

Anónimo. "Cuentos completos de J.C.O.", El Mercurio (Valparaíso), 29 junio 1969.

_- "Cuentos completos de J.C.O.", Semana (Caracas), 28 nov. $/ 5$ dic. 1968.

__. "Formidable Onetti", Siete Dias-Siete Libros (Lima), 22 junio 1969. [Sobre Cuentos completos y Novelas cortas completas].

- - "J.C.O.: Juntacadáveres", Cuademos para el diálogo (Madrid), No. 80, mayo de 1970.

- "J. C. Onetti", Panorama (Buenos Aires), No. 138, 27 enero 1970. [Indice de personalidades].

-. "J. C. Onetti", Ultimas Noticias (Caracas), 3 agosto 1969. [Sobre Recopilación de textos sobre ].C.O.].

—. "J.C.O. La vita breve", La Domenica del Corriere (Milano), 10 novembre 1970.

_. "J.C.O. Obras completas", La Mañana (Montevideo), 1 octubre 1970, p. 9.

-... "J.C.O.: Raccattacadaveri", Il Tempo (Roma), 12 ottobre 1969.

—. "Juntacadáveres", Revista Oiga (Lima), 3 julio 1970. 
- "Los libros recomendados: Juntacadáveres de Onetti", Soria, Ho. gar y Pueblo (España), 8 julio 1970.

_.. "Onetti en francés", Acción, 14 abril 1972.

-. "Onetti, Onetti, Onettí, O’Netty", Acción, 6 noviembre 1970. [Sobre las Obras completas].

—. "Por fin, Juntacadáveres", El correo de Andalucia, 5 junio 1970.

-. "Raccattacadaveri", Domini e Libri (Milano), Ottobre 1969.

—. "Southern Crosses", The Times Literary Supplement, No. 3,318, 30 September 1965, pp. 867-68. [Sobre la novela hispanoamericana; El astillero y "El infierno tan temido", p. 867]

—. "The Shipyard", Publisher's Weekly, Vol. 193, No. 12, 18 March 1968 , p. 48.

-.."Un mondo disperato", Messaggero Veneto (Udine), 15 novembre 1970. [Sobre La vida breve].

_- "Viene a España J.C.O.", Pueblo, 17 junio 1970. [No fue].

Aldrich, Earl M. "La cara de la desgracia", Handbook of Latin American Studies, No. 25, Gainesville: Univ. of Florida Press, 1963, p. 318. En el No. 26, 1964, p. 170: "El astillero". En el No. 28, 1966, pp. 272-73: "El infierno tan temido", "Juntacadáveres", "El pozo", "Tan triste como ella". En el No. 30, 1968, p. 279: "Cuen. tos completos", "Jacob y el otro", "Tierra de nadie". En el No. 32, 1970, p. 396: "Novelas cortas".

Aubrun, Charles. Histoire des Lettres Hispano-Americaines. Paris Lib. A. Colin, 1954, p. 206.

Bellini, Giuseppe. La letteratura ispano-americana dalle letterature precolombine ai nostri giorni. Milano: Sansoni-Accademia, 1970, p. 419.

Brughetti, Romualdo. "Una nueva generación argentina (1940-1950)", Cuadernos americanos (mayo-junio 1952), pp. 261-281.

Castelli, Eugenio. Tres planos en la expresión literaria bispanoamericana. Santa Fe, Argentina: Colmegna, 1967, p. 82.

Ferreira, Joao Francisco. Capítulos de literatura hispanoamericana. Porto Alegre: Fac. Fil. da U.R.G.S., 1959.

Flesca, Juan José. "Cuatro escritores uruguayos", La Prensa, 27 sept. 1964, p. 4. [Reseña de Tan triste como ella].

Gándara, Carmen. "Vicisitudes de la novela", Realidad, Vol 5, No 13 (1949), pp. 32-41. [Tier ra de nadie].

García, Germán. La novela argentina. Buenos Aires: Sudamericana, 1952, p. 214. 
Gramigna, Giuliano. "La vita breve e un'autobiografía", Corriere D'Informazione (Milano), 14 dicembre 1970.

Gutiérrez Girardot, Rafael. "Modernidad y trivialización", La Nación, $4^{a}$ sección, 28 junio 1970 , pp. 1 y 3 . [Sobre la novela hispanoamericana].

Laaths, Erwin. Historia de la literatura universal. Barcelona, Ed. Labor, 1967, p. 757.

Latchan, Ricardo A. "Perspectivas de la literatura hispanoamericana contemporánea", Atenea, No. 380-381 (abril-sept. 1958), pp. 305 336. [Esp. pp. 333-34].

Jeal, Luis. El cuento bispanoamericano. Buenos Aires: Centro Editor de América Latina, 1967, pp. 46-47.

Leavitt, Sturgis E. "Tierra de nadie", Handbook of Latin American Studies. No. 7, Cambridge: Harvard Univ. Press, 1942, p. 453.

Leguizamón, Julio A. Historia de la literatura bispanoamericana. Vol. II, Buenos Aires: Editoriales Reunidas, S. A., 1945, p. 473.

Leward, H. Ernest. "The 1965 Literary Scene in Argentina and Uruguay", Books Abroad (Spring 1966), pp. 145.48. [Esp. p. 147].

Luzi, Mario. "Fantasie Spagnole", Corriere della Sera (Milano), 31 dicembre 1970. [Sobre La vida breve].

Magis, Carlos Horacio. La literatura argentina. México: Editorial Pormaca, 1965, p. 305.

Meléndez, Concha. "La vida breve", Handbook of Latin American Studies. No. 16, Gainesville, Univ. of Florida Press, 1953, pp. 221-22. En el No. 17, 1954, p. 122: "Un sueño realizado y otros cuentos".

Neale-Silva, Eduardo. "Los adioses", Handbook of Latin American Studies, No. 22, Gainesville, Univ. of Florida Press, 1960, pp. 263-64.

Pastor, Miguel Angel. "Juntacadáveres de J.C.O.", El Norte de Castilla, 9 octubre 1970.

Pinto, Juan. Breviario de literatura argentina contemporánea. Buenos Aires: Editorial La Mandrágora, 1958, p. 122.

Schwartz, Kessel. The Meaning of Existence in Contemporary Hispanic Literature. Coral Gables: University of Miami Press, 1969, p. 23.

Torres Rioseco, Arturo. Nueva bistoria de la gran literatura iberoamericana. 3? ed. Buenos Aires: Emecé, 1960, p. 312.

Vargas Llosa, Mario. "La literatura es una forma de insurrección permanente", Revista Nacional de Cultura, No. 181, (julio/agosto/sept. 1967), pp. 99-102. Reproducido en Mundo Nuevo, No, 17 (noviembre 1967), pp. 93-95, con el título "La literatura es fuego". 